\title{
Ortaokul Öğrencilerinin Örüntü Problemlerini Çözme Başarılarının Çeşitli Değişkenler Açısından İncelenmesi"
}

\section{Investigation of Secondary School Students' Success in Solving Pattern Problems in Terms of Various Variables}

\author{
Aygil TAKIR ${ }^{1}$, Ayşen ÖZEREM ${ }^{2}$
}

• Geliş Tarihi: 06.02.2019 • Kabul Tarihi: 07.01.2020 • Çevrimiçi Yayın Tarihi: 07.01.2020

\section{$\ddot{O} \mathbf{z}$}

$\mathrm{Bu}$ araştırmanın amacı ortaokul öğrencilerinin sınıf düzeyi, cinsiyet ve matematik başarıları ile örüntü problemlerini çözme başarıları arasında anlamlı bir ilişki olup olmadığını belirlemektir. Araştırmada tarama modeli kullanılmıştır. Araştırmanın örneklemini, Kuzey Kıbrıs Türk Cumhuriyeti Lefkoşa ilçesine bağlı bir devlet kolejinde öğrenim gören 399 öğrenci oluşturmaktadır. Araştırmada veri toplama aracı olarak Örüntü Başarı Testi kullanılmış ve veriler çoklu regresyon yardımıyla analiz edilmiştir Araştırma sonuçları ortaokul öğrencilerinin iyi düzeyde örüntü problemlerini çözme başarısına sahip olduklarını göstermektedir. Bağımsız değişkenler olarak ele alınan sınıf düzeyi, cinsiyet ve matematik başarısının, öğrencilerin örüntü problemlerini çözme başarısını pozitif ve orta düzeyde yordadığı görülmüştür.

Anahtar sözcükler: Örüntü, Örüntü Başarısı, Genelleme, Çoklu Regresyon Analizi

Atıf:

Takır, A. ve Özerem, A. (2020). Ortaokul öğrencilerinin örüntü problemlerini çözme başarılarının çeşitli değişkenler açısından incelenmesi. Pamukkale Üniversitesi Ĕ̆itim Fakültesi Dergisi, 49, 582599. doi: 10.9779/pauefd.523388.

\footnotetext{
* Bu çalışma, 04-06 Ekim 2018 tarihinde Pamukkale Üniversitesi Eğitim Fakültesinde düzenlenen 13. Ulusal Fen Bilimleri ve Matematik Ĕgitimi Kongresi'nde bildiri olarak sunulmuştur.

1 Dr. Öğretim Üyesi, Doğu Akdeniz Üniveristesi, aygil.takir@,emu.edu.tr, https://orcid.org/0000-0003-3042-7585

2 Dr. Öğretmen, Milli Eğitim Bakanlığı, aysenozerem@yahoo.com, https://orcid.org/0000-0001-6779-2960
} 


\begin{abstract}
The purpose of this study was to determine whether there is a significant relationship between the grade level, gender and mathematics achievement of secondary school students and their success in solving pattern problems. For this purpose, descriptive study was conducted totally 399 middle school students enrolled at a state college in the Nicosia district of the Turkish Republic of Northern Cyprus. The data was collected by Pattern Achievement Test and analyzed by multiple regression analysis. It was seen that class level, gender and mathematics achievement, which are considered as independent variables, had a positive and moderate level impact on students' success in solving pattern problems.
\end{abstract}

Keywords: Pattern, Pattern Success, Generalization, Multiple Regression Analysis

\title{
Cited:
}

Takır, A. \& Özerem, A. (2020). Investigation of secondary school students' success in solving pattern problems in terms of various variables. Pamukkale Üniversitesi Eğitim Fakültesi Dergisi49, 582599. doi: 10.9779/pauefd.523388. 


\section{Giriș}

Matematik, bir örüntü ve ilişkiler bilimi olarak tanımlanmaktadır (Steen, 1990). Matematiksel gelişmenin temel bir öğesi ve sorgulamanın merkez bir yapısı (Olkun ve Tanışl1, 2009) olan örüntüler matematiğin bütününde yer almaktadır. Matematiksel ilişkileri görmede, genelleme yapmada, matematiğin düzenini ve mantığını anlamada temel olan (Burns, 2000) örüntüler aynı zamanda matematiksel ilişki kurmada, fonksiyonel ve cebirsel düşünmede (Tall, 1992), problem çözme stratejileri geliştirmede (Hargreaves, Shorrocks ve Threlfall, 1998; Mor, Noss, Hoyles, Kahn ve Simpson, 2006) anahtar bir kavramdır. Söz edilen bu becerilerin geliş̧imindeki rolünden dolayı örüntü konusu okul öncesinden itibaren tüm sınıf düzeylerinde yer almaktadır.

Türk Dil Kurumu örüntü kavramını, "olay veya nesnelerin düzenli bir biçimde birbirini takip ederek gelişmesi” şeklinde tanımlanmaktadır. Papic ve Mulligan (2005) örüntüyü, sayısal ya da uzaysal düzenliliktir şeklinde, Olkun ve Toluk-Uçar (2007) ise düzenli dizilmiş nesne ya da şekillerin oluşturduğu manzume şeklinde tanımlamışlardır.

Örüntüler, yapılarına göre çeşitlilik göstermektedirler: tekrarlayan ve değişen örüntüler. Tekrarlanan örüntüler, tekrar birimi olarak ifade edilen, belirli birtakım öğelerin döngüsel olarak devam ettiği örüntülerdir (Threlfall, 1999). Terimler arası ilişkinin sabit bir dizilimin ötelemesi şeklinde olan örüntüler tekrarlayan örüntüler; terimler arası ilişkinin genişleyen veya daralan bir seyir izlemesi şeklinde olan örüntüler ise değişen örüntüler olarak adlandırılır (Tanışlı ve Olkun, 2009). Tekrarlanan örüntülerde, tekrar biriminin ne olduğunun algılanmasına dayalı olarak genellemelere ulaşılır. Değişen örüntülerde genellemeye ulaşmak için ise iki ana stratejiden bahsedilmektedir: yinelemeli ve değişkenler arası ilişki bulma. Yinelemeli strateji, örüntünün bir önceki teriminden yararlanarak bir sonraki terimini bulmayı içermektedir. Araştırmalar çocukların (Orton ve Orton, 1999) bir örüntü problemi ile karşılaştıklarında yinelemeli bir yaklaşım kullanmaya eğilimleri olduğunu göstermektedir. Bu stratejiyi kullanan öğrenciler örüntüyü tanımlayabilir ve sürdürebilirken bu örüntünün altında yatan matematiksel fonksiyonu anlamakta zorlanmaktadır (Frobisher ve Threlfall, 1999, Warren, 2005). Değişkenler arası ilişki bulma stratejisi ise iki değişken arasındaki ilişkinin genellemesinin gerektiği stratejidir. Diğer bir deyişle bir veri setindeki ilişkiden ziyade iki veri setindeki ilişkidir (Warren ve Cooper, 2007). Değiş̧kenler arası ilişki bulma stratejisi kullanıldığında iki değişken arasındaki kural genellenerek, elde edilen genel kural, istenilen herhangi bir değerin belirlenmesi için kullanılabilir.

Matematiğin temelini oluşturan Cebir, sembollerin aritmetik işlemlerin bir uygulaması olmasından genellikle aritmetiğin genellemesi olarak tanımlanır. Genelleştirilmiş aritmetik, aritmetiksel işlemlerin soyutlanması ile oluşur. Yani aritmetiğin sembolik tarafidır. Cebirsel düşünme ise değişkenler arasındaki ilişkilerin görünür olması için sayısal durumların temsil edilme yeteneği olarak tanımlanır. Cebirsel düşünme örüntülerin keşfedilmesi ile başlar. Diğer bir deyişle, cebirsel düşünmenin temelinde örüntü arama ve genelleme vardır. Örüntüler, sembolleri yorumlamayı öğrenmede bir araç olup, ilerde karşılaşılan sayılar ve şekiller ile ilgili genel ifadeleri oluşturmayı ve tanımayı sağlarlar. Bu sebeple örüntüler cebir için bir köşe taşı durumundadir (Threlfall, 1999).

İlgili alanyazın incelendiğinde, örüntüler ile ilgili yapılan çalışmaların, verilen eğitimin öğrencilerin örüntü genellemeleri üzerindeki etkisini araştıran (Dyndial,2007; Orton ve Orton, 1994; Moss ve Beaty, 2006; MacGregor ve Stacey, 1993; Becker ve Rivera, 2006, Tanışlı ve 
Köse, 2011), öğrencilerin örüntüleri çözmede kullandıkları stratejileri araştıran (Lan Ma, 2007; Becker ve Rivera, 2005; Tanışl1, 2008; Hargreaves, Shorrocks ve Threlfall, 1998; Özdemir, Dikici ve Kültür, 2014; Pilten ve Yener, 2009; Tanışlı, Köse ve Camcı, 2017) ve örüntü sunum biçimlerinin öğrencilerin örüntü performanslarına etkisini araştıran (Looney, 2004; Tsankova; 2003) şeklinde sınıflandırılabileceği görülmüştür. Özelde, örüntü başarısının araştırıldığı çalışmalara bakıldığında, Yaman (2010), 3.-7. sınıf arasındaki öğrenciler ile yaptığı araştırmada öğrencilerin sınıf seviyelerine göre matematiksel örüntü performansları arasında anlamlı farklılıklar olduğunu ortaya koymuştur. Sınıf seviyesi arttıkça öğrencilerin matematiksel örüntü performanslarının artı̆̆ çalışmanın bulguları arasındadır. Araştırmada kullanılan örüntü başarı testinde en yüksek ortalamayı 7. sinıflar elde ederken sonrasında sirasıyla 6, 5, 4 ve 3. sinıflarda gelmektedir. Looney (2004) 3., 4. ve 5. sınıf öğrenciler ile yaptığı araştırmada, öğrencilerin bir örüntüyü devam ettirme, örüntünün terimleri arasındaki ilişkiyi sözel olarak ifade etme ve örüntünün terimleri arasındaki ilişkiyi sembolik olarak ifade etme görevlerinde ne kadar başarılı olduklarını belirlemeyi amaçlamıştır. Araştırma sonuçları, 5. sınıf öğrencilerinin, 4. ve 3. sınıf öğrencilerine göre örüntü konularında daha başarılı olduklarını ortaya koymuştur. Dobrynina (2001) çalışmasında 5. ve 6. sınıf öğrencilerinin örüntüleri genelleme başarılarının 4. sınıf öğrencilerinin başarılarından istatistiksel olarak anlamlı bir şekilde daha yüksek olduğunu ve ögrencilerin bir veri setine odaklanan stratejileri (yinelemeli stratejileri) daha sık, iki veri setine odaklanan stratejileri (değişkenler arası ilişki bulma) ise daha az kullandıklarını belirlemiştir.

Matematik eğitimcileri günümüzde cebir için basamaklı ve gelişime dayalı bir eğitim önermektedirler (Fouche, 1997; Willoughby, 1997). Böyle bir eğitiminde okulöncesi dönemden itibaren cebirsel kavramların verilmeye başlanmasıyla mümkün olacağı ifade edilmektedir (Yackel, 1997; Orton ve Orton, 1999). KKTC'de önceki programlarda ortaokul yıllarında başlayan cebir öğretimi, 2005 yılında değiştirilen öğretim programları ile birlikte okul öncesi dönemden itibaren başlamaktadır. Bu araştırmanın amacı ortaokul öğrencilerinin sınıf düzeyi, cinsiyet ve matematik başarıları ile örüntü başarıları arasında anlamlı bir ilişki olup olmadığını belirlemektir. Bu bağlamda öğrencilerin örüntülere ilişkin başarıları belirlenerek, öğrencilerde cebirsel düşünme ve fonksiyon kavramının gelişimine destek olma konusunda veri sağlanması amaçlanmıştır. Ortaokul öğrencilerinin örüntü ve ilişkiler konularında ne kadar iyi olurlarsa lise yıllarında cebir konularına o kadar sağlam bir temelle geçeceklerdir. Bu bağlamda bu çalışma sonucunda ortaya konulacak sonuçların KKTC'de matematik eğitimi alanında yapılan çalışmalara katkı sağlayacağı düşünülmektedir. Alanyazına bağlı kalınarak bu araştırmada ele alınan cinsiyet, sınıf düzeyi ve matematik değişkenlerinin bazı çalışmalarda öğrencilerin örüntü başarılarında ayırt edici değişkenler olduğu gözlemlenmiş (Dobrynina, 2001; Looney, 2004; Tsankova; 2003; Yaman, 2010) ve bu çalışmada etkileri değerlendirilmek üzere seçilmişlerdir.

Araştırmanın temel amacı doğrultusunda şu sorulara yanıt aranmıştır:

1. Ortaokul öğrencilerinin örüntü problemlerini çözme başarıları ne düzeydedir?

2. Sınıf düzeyi, cinsiyet ve matematik başarısı birlikte örüntü başarısını anlamlı şekilde yordamakta midır?

\section{Araştırmanın Gerçekleştirildiği Okulun Özellikleri}

KKTC eğitim sistemine göre ortaokul basamağ 6,7 ve 8 . sınıf düzeylerinden oluşmaktadır. Araştırma, bir devlet kolejinde gerçekleştirilmiştir. KKTC'de eğitim-öğretim hizmeti veren devlet kolejleri sınav ile öğrenci almakta ve KKTC-Türkiye'deki üniversitelere ve üçüncü 
dünya ülkelerine öğrenci hazırlamaktadır. Bu kolejlerin eğitim dili İngilizcedir. Okulda farklı ülkelerden gelen yabancı uyruklu öğrenciler de bulunmaktadır.

\section{Yöntem}

Araştırmada, ortaokul öğrencilerinin örüntü problemlerini çözmeye yönelik olarak başarılarını araştırmak amaçladığından tarama modeli kullanılmıştır. Tarama modelleri, geçmişte ya da halen var olan bir durumu var olduğu şekliyle betimlemeyi amaçlayan araştırma yaklaşımlarıdır (Karasar, 2015).

\section{Örneklem}

Araştırmanın evrenini 2017-2018 eğitim-öğretim yılında KKTC'de öğrenin gören tüm ortaokul öğrencileri oluşturmaktadır. Araştırmanın örneklemi uygun örnekleme (convenience sampling) yoluyla belirlenen, KKTC'de bir devlet kolejinde öğrenim gören 399 öğrencidir. Uygun örneklemede, araştırmacılar katılımcıları ulaşması kolay, araştırma için uygun ve gönüllü bireylerden seçmektedir (Gravetter ve Forzano, 2012). Çalışmaya katılan öğrencilerin 187'si (\%47) erkek, 212'si (\%53) kıdır; 141'i (\%35.3) 6. sinıf, 119’u (\%29.8.8) 7.sinıf ve 139’u (\%34) 8.sinıf öğrencisidir.

Öğrencilerin matematik başarılarına göre betimsel istatistik bilgileri Tablo 1'de verilmiştir. KKTC okullarında öğrencilerin karne başarı notları belirlenirken (ödev notu x 1+ara sinav notu x 2+final sınavı x 3)/6 formülü ile öğrencinin dönem sonu ders notu hesaplanmakta ve karne notu belirlenirken şu not aralıkları kullanılmaktadır: 95-100: 10; 85-94: 9; 75-84: 8; 65-74: 7; 55-64: 6; 45-54: 5; 35-44: 4; 25-33: 3; 15-23: 2; 0-14: 1

Tablo 1. Matematik başarısına göre istatistik bilgiler

\begin{tabular}{cccc}
\hline Matematik Notu & $\%$ & Matematik Notu & $\%$ \\
\hline 1 & 0.5 & 6 & 6.5 \\
2 & 0.3 & 7 & 13.5 \\
3 & 0.8 & 8 & 25.8 \\
4 & 2.8 & 9 & 28.1 \\
5 & 3.5 & 10 & 18.3 \\
\hline
\end{tabular}

Tablo 1'de görüldüğü gibi öğrenciler en çok sırasıyla 9,8 ve 10 matematik başarı puanına sahiptir. Araştırmaya katılan öğrencilerin matematik notu ortalaması 8.03 'tür.

\section{Değişkenler}

Araştırmada, üç bağımsız ve bir bağımlı değişken ele alınmıştır. Sınıf düzeyi, cinsiyet ve matematik başarısı bağımsız değişkenler, örüntü testinden aldıkları puanlar ise bağımlı değişken olarak tanımlanmıştır.

\section{Çalışmada Kullanılan Ölçme Aracı}

Araştırmada, veri toplamak amacıyla araştırmacılar tarafindan geliştirilen 10 soruluk Örüntü Başarı Testi (ÖBT) kullanılmıştır. ÖBT'de kullanılan sorular araştırmanın amacı, literatür taramasından elde edilen bilgiler, ilkokul ve devlet kolejlerinde uygulanan matematik 
programındaki kazanımlar ile uzman görüşleri alınarak oluşturulmuştur. Devlet kolejlerinde uygulanan matematik programında örüntüler konusu Cebir Öğrenme Alanında yer almaktadır. Tablo 2'de ilkokul ve devlet kolejlerinde uygulanan matematik programındaki örüntü kazanımlarına yer verilmiştir.

\section{Tablo 2. İlkokul ve Ortaokul Matematik Programlarında Örüntü Kazanımları}

\begin{tabular}{|c|c|}
\hline 1. Sinif & $\begin{array}{l}\text { Genel kuralı verilen bir örüntüde eksik bırakılan ögeyi bulur. } \\
\text { Basit öğelerle süslemeler oluşturur. } \\
\text { Belirli bir kurala göre oluşturulan bir süslemede kuralı bozan öğeleri tespit eder. }\end{array}$ \\
\hline 2. Sinif & $\begin{array}{l}\text { Bir örüntüde eksik bırakılan ögeleri belirleyerek tamamlar. } \\
\text { Bir örüntüdeki genel kuralı bulur. } \\
\text { Bir örüntüdeki ilişkiyi kullanarak farklı malzemelerle aynı ilişkiye sahip yeni örüntüler } \\
\text { oluşturur. }\end{array}$ \\
\hline 3. Sinif & $\begin{array}{l}\text { Bir örüntüde eksik bırakılan ögeleri belirleyerek tamamlar. } \\
\text { Tamamlanmış bir sekil örüntüsündeki genel kuralı bulur. } \\
\text { Bir örüntüdeki ilişkiyi kullanarak farklı malzemelerle aynı ilişkiye sahip yeni örüntüler } \\
\text { oluşturur. }\end{array}$ \\
\hline 5. Sinif & $\begin{array}{l}\text { Kuralı verilen bir örüntüyü genişletir. } \\
\text { Örüntüyle ilgili problem çözer veya kurar. }\end{array}$ \\
\hline 6. Sinif & $\begin{array}{l}\text { Aritmetik dizilerin kuralını harfle ifade eder, kuralı harfle ifade edilen dizinin istenilen } \\
\text { terimini bulur. }\end{array}$ \\
\hline 8. Sinif & $\begin{array}{l}\text { Bir örüntünün kuralını harfle ifade eder, kuralı harfle ifade edilen örüntünün istenilen } \\
\text { terimini bulur. }\end{array}$ \\
\hline
\end{tabular}

ÖBT'de kazanımlara uygun olarak şekil, tablo, sayı dizisi ve sözel problem şeklinde örüntü sunum biçimlerine yer verilmiştir. Ayrıca, yakın/uzak terimi bulma, tanımlama ve sembolize etmeye yönelik sorular bulunmaktadır. Testteki tüm örüntü soruları Değişen Örüntü şeklindedir. Değişen örüntüler aritmetik, geometrik veya artarak genişleyen örüntüler şeklinde sınıflandırılmaktadır (Özdemir, Dikici ve Kültür, 2014). Çalışmada sadece aritmetik artarak değişen örüntülere yer verilmiştir. Bu örüntülerin kuralları an+b şeklindedir. Kural örüntünün tüm elemanları için geçerli olduğundan kaçıncı terimi sorulursa sorulsun öğrencilerin o elemanın hangi sayı olması gerektiğini bulmaları gerekmektedir. Çalışmada aritmetik artarak değişen örüntülere yer verilmesinin sebebi, çalışmanın yapıldığ matematik programında sadece bu tip örüntülere yer verilmesidir. ÖBT’de soru kökleri İngilizce olarak yazılmıştır. ÖBT'de kullanılan örnek sorular Tablo 3’te verilmiştir.

Testin puanlanması her bir sorunun içerdiği alt sorular üzerinden yapılmıştır. Örneğin, yakın/uzak terimi bulma sorularında hep örüntünün iki elemanının bulunması istenmiştir. İki elemanı da bulan öğrenciye 2 puan, 1 elemanı bulan öğrenciye 1 puan, ikisini de bulamayan öğrenciye 0 puan verilmiştir. Örüntüyü sözel olarak tanımlama sorularında ise bulduğu kuralı sözel olarak ifade edip bu sözel ifadeyi yazabilen öğrenciye 1 puan, yazamayan öğrenciye ise 0 puan verilmiştir. Örüntüyü sembollerle ifade etme sorularında ise bulduğu kuralı tam olarak sembolize eden öğrenciye 2 puan, kuralı bulamayan ya da bulsa da sembolize edemeyen öğrenciye ise 0 puan verilmiştir. Her bir öğrencinin toplam puanı bu puanlama sistemi üzerinden hesaplanmıştır.

Testin uygulamasına geçilmeden önce testte yer alan sorular açıklık, anlaşılırlık ve içerik bakımından, iki matematik öğretmeni tarafından incelenmiştir. Öğretmenlerin önerileri 
doğrultusunda bazı soruların ifadeleri ve sıralamaları değiştirilerek teste son hali verilmiştir. Daha sonra, soruların işlerliğini değerlendirmek amacıyla 5 öğrenciyle pilot uygulama yapılmıştır. Pilot uygulama sonuçları, soruların öğrenciler için açıklığı, anlaşılırlığı ve verdikleri cevapların tutarlılığını ölçmek amacıyla araştırmacılar tarafından incelenmiştir. Bu çalışma sonucunda, soruların öğrenciler tarafindan açık ve anlaşılır olduğu, aynı zamanda test sorularında herhangi bir hata olmadığı ortaya konularak uygulamaya geçilmiştir.

Tablo 3. Örüntü Başarı Testinde (ÖBT) kullanılan örnek sorular

\begin{tabular}{|c|c|}
\hline Soru & $\begin{array}{lr}\text { Örüntü } & \text { Sunum } \\
\text { Biçimi } & \text { ve } \\
\text { Beceriler } & \\
\end{array}$ \\
\hline $\begin{array}{l}\text { Here are the first five terms of an arithmetic sequence. } \\
7,11,15,19,23 \\
\text { a) Write down, in terms of n, an expression for the nth term of this sequence. } \\
\text { b) Pat says that } 453 \text { is a term in this sequence. Pat is wrong. Explain why. } \\
\text { (Bir aritmetik dizinin ilk beş terimi aşağıdaki gibidir: } \\
7,11,15,19,23 \\
\text { a) n. terim için n cinsinden bir ifade yazınız. } \\
\text { b) } 453 \text { 'ün bu örüntünün bir terimi olduğunu söyleyen Pat yanlış cevap } \\
\text { vermektedir. Nedenini açıklayınız.) }\end{array}$ & $\begin{array}{l}\text { Sayı dizisi } \\
\text { örüntüsünü } \\
\text { Yakın/uzak } \\
\text { terimi bulma, } \\
\text { tanımlama ve } \\
\text { sembolize etme }\end{array}$ \\
\hline $\begin{array}{l}\text { a) Write down the number of in each of these patterns. } \\
\text { b) Draw the next two patterns. } \\
\text { c) Write down the rule in words to continue the pattern. } \\
\text { d) Use your rule to find the number of matches needed for pattern number } 10 \text {. } \\
\text { (a) Her biri şekil için kaç tane kibrit çöpü kullanıldığını yazınız. b) Sonraki iki } \\
\text { şekli çiziniz. c) Örüntüdeki kuralı belirten bir cümle yazınız. d) 10. Şekil için kaç } \\
\text { çöp kullanılması gerektiğini bulunuz) }\end{array}$ & $\begin{array}{l}\text { Şekil örüntüsü } \\
\text { Yakın/uzak } \\
\text { terimi bulma, } \\
\text { tanımlama ve } \\
\text { sembolize etme }\end{array}$ \\
\hline $\begin{array}{l}\text { a) The first term of sequence is }-5 \text {. The rule of for continuing the sequence } \\
\text { "multiply by } 4 \text { then subtract } 3 \text { ". What is the second term of the sequence? } \\
\text { b) Here a rule for continuing a different sequence: "Add } 4 \text { then multiply by } 2 \text { ". } \\
\text { The second term of this sequence is } 20 \text {. What is the first term? } \\
\text { (a) Bir örüntüdeki ilk terim -5'tir. } \\
\text { Kural: } 4 \text { ile çarp } 3 \text { eksilt uygulanırsa ikinci terim ne olur? } \\
\text { b) Farklı bir örüntü için Kural: } 4 \text { ekle } 2 \text { ile çarp. İkinci terim } 20 \text { ise ilk terim } \\
\text { nedir? }\end{array}$ & $\begin{array}{l}\text { Sözel olarak } \\
\text { ifade edilmiş } \\
\text { örüntü } \\
\text { Yakın/uzak } \\
\text { terimi bulma, } \\
\text { tanımlama }\end{array}$ \\
\hline
\end{tabular}

Uygulamanın başında ortaokul öğrencilerinden ölçme aracının başında yer alan sınıf düzeyi, cinsiyet ve matematik karne notu kısımlarını doldurmaları istenmiştir. Örüntü testinde her soru farklı puana sahip olup testten alınabilecek en yüksek puan 45, en düşük puan 0'dır.

Araştırma için geliştirilen veri toplama araçları, araştırmanın amacını gerçekleştirmeyi sağlayacak yeterli ve geçerli bilgileri yansıtacak nitelikte olduğu varsayılmış ve katılımcı öğrencilerin örüntü testindeki sorulara içtenlikle cevap verdikleri varsayılmıştır. 


\section{İșlem}

ÖBT öğrencilere dağıtılmış ve cevaplamaları için 40 dakika süre verilmiştir. Çalışmanın verileri 2017-2018 eğitim-öğretim yılı bahar döneminde toplanmıştır. Araştırmaya katılan öğrencilere uygulamaya başlamadan önce "Bilgilendirilmiş Onay Formu" okutulup, imzalatılmıştır. Öğrenciler 18 yaşından küçük oldukları için araştırmaya katılımları için velilerinden de izin alınmıştır. Uygulanmadan önce öğrencilere testin konusu ve cevaplama süresi hakkında bilgi verilmiştir.

\section{Veri Analizi}

Veri analizini gerçekleştirmek için bir istatistik paket programından yararlanılmıştır. Ortaokul öğrencilerinin sınıf düzeyi, cinsiyet ve matematik başarıları ile örüntü başarıları arasında anlamlı bir ilişki olup olmadığını araştırmak amaçlandığından çoklu regresyon analizi kullanılmıştır. Regresyon analizinde bağımlı ve bağımsız değişkenlerin en az eşit aralık ölçeğinde sürekli değişkenler olması gerektiğinden analizde sınıflama değişkeni olan sınıf düzeyi, düzeylerinden biri dışarıda tutularak düzey sayısının bir eksiği kadar üretilen 'kukla (dummy)' değişkene dönüştürülmüş ve analiz edilmiştir. Cinsiyet değişkeni ise 0 ve 1 olarak kodlanmıştır. Araştırmanın 'kukla (dummy)' değişken kodlaması Tablo 4'te verilmiştir.

Tablo 4. Dummy değişken kodlaması

\begin{tabular}{lllll}
\hline Değişken & Düzey & $\begin{array}{l}\text { Kukla (Dummy) } \\
\text { Değişken }\end{array}$ & Kodlama & $\begin{array}{l}\text { Dışta } \\
\text { Kategori }\end{array}$ \\
\hline Sınıf Düzeyi & 1. 6.Sınıf & Sınıf1 & 6.Sınıf:1; & 8.Sınıf \\
& 2. 7. Sınıf & Sınıf2 & Diğerleri:0 & \\
Cinsiyet & 1. Erkek & Cins & Erkek:1; Kız:0 & Kız \\
& 2. Kız & & & \\
\hline
\end{tabular}

Çoklu regresyon analizinin yapılabilmesi için öncelikle gerekli olan varsayımlar incelenmiştir. Bunlardan ilki olan hatalar için doğrusallık ve normallik varsayımları grafikler yardımıyla incelenerek (Şekil 1), standardize edilmiş artık değerler ile standardize edilmiş yordanan değerler için noktaların bir eksen etrafında toplanma eğiliminde olduğu görülmüştür. Standardize edilmiş yordanan değerler için oluşturulan histogram ve normal dağılım eğrilerinin de normale yaklaşık bir dağılım gösterdikleri anlaşılmış ve hatalar için doğrusallık ve normallik varsayımlarının sağlandığı kabul edilmiştir.

Bağımsız değişkenler arasında güçlü ilişki olmadığına ilişkin olan çoklu bağlantılılık (multicolinearity) varsayımı için bağımsız değişkenler arasındaki ikili korelasyonlar incelenmiş (Tablo 4) ve varyans büyüme faktörü (VIF) ile tolerans değerleri hesaplanmıştır. Her bir değişken için VIF değerleri 1.006 ile 1.353 arasında olup 4’ten küçük olma şartını sağlamaktadır. Tolerans değerlerinin ise her bir değişken için 0.73 ile 0.99 arasında değişerek 0.20 'den büyük olma şartını sağladıkları görülmüştür. 


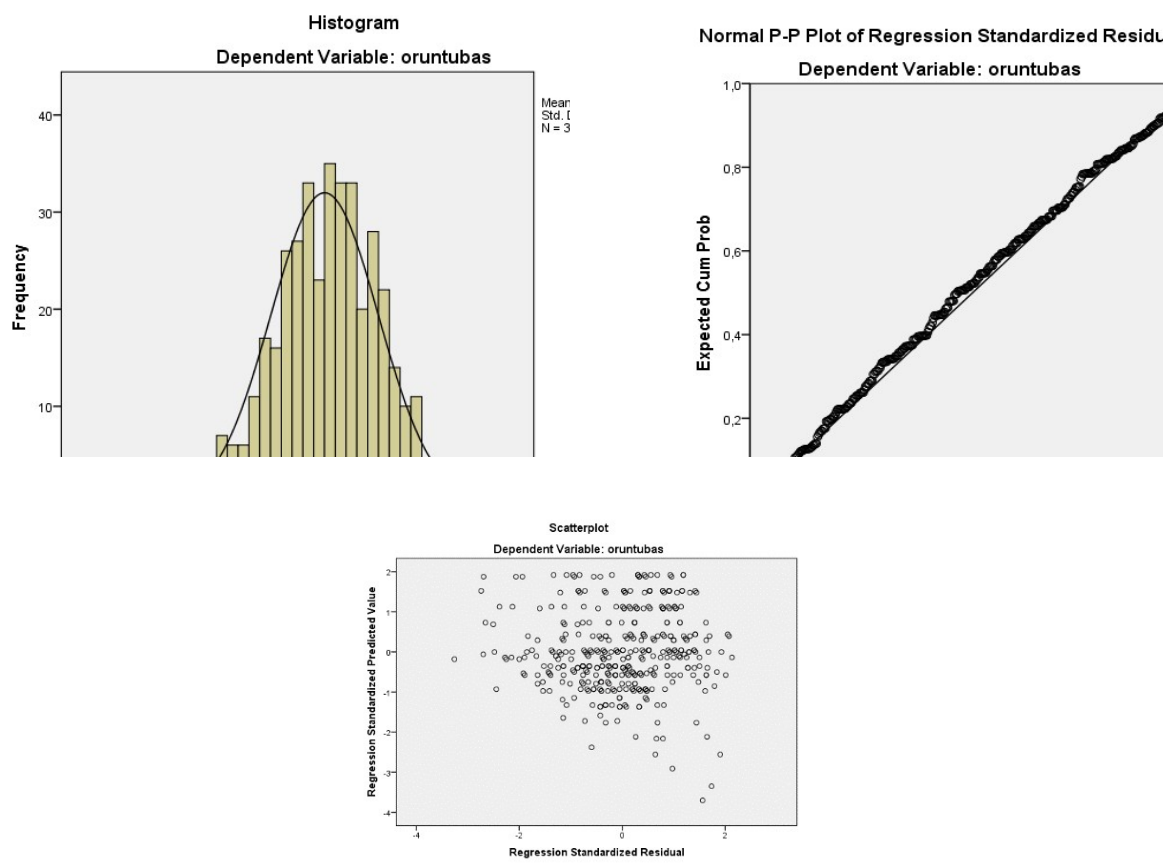

Şekil1. Doğrusallık ve normallik varsayımlarının incelenmesi

Çalışmaya dâhil edilen örüntü başarısı, sınıf düzeyi, cinsiyet ve matematik başarısı değişkenlerinin ortalama ve standart sapma değerleri ile değişkenlerin birbirleri arasındaki korelasyonları araştırılmış ve Tablo 5'te sunulmuştur.

Tablo 5. Korelasyon katsayıları $(n=399)$

\begin{tabular}{llllll}
\hline & Örüntü Başarıs1 & Sinıf1 & Sinıf2 & Cins & Matematik Başarıs1 \\
\hline Örüntü Başarıs1 & 1.000 & & & & \\
Sinıf1 & -0.081 & 1.000 & & & \\
Sinıf2 & -0.294 & -0.482 & 1.000 & & \\
Cins & -0.040 & 0.031 & 0.046 & 1.000 & \\
Matematik Başarıs1 & 0.261 & 0.147 & 0.029 & 0.014 & 1.000 \\
Aritmetik Ortalama & 26.72 & 0.3534 & 0.2982 & 0.47 & 8.08 \\
Standart Sapma & 9.156 & 0.47862 & 0.45806 & 0.500 & 1.640 \\
\hline
\end{tabular}

Tablo 4'e göre sınıf düzeyi, cinsiyet ve matematik başarısı değişkenleri ile bağımlı değişken arasında korelasyonlar incelendiğinde, istatistiksel olarak anlaml, pozitif ve zayıf düzeyde ilişki görülmektedir $(r=.26)$. Öte yandan, örüntü başarısı ile sınıf düzeyi arasında istatistiksel olarak anlamlı, negatif ve zayıf düzeyde ilişki görülmektedir: $(r=.29)$. Buna göre, kolerasyon tablosu, VIF ve tolerans değerlerine bakıldığında değişkenler arasında çoklu bağlantı olmadığı söylenebilir.

Regresyon analizinin diğer bir varsayımı hataların ilişkisiz olması durumudur. $\mathrm{Bu}$ varsayımın sağlanmadığı durumlarda verilere karışan sistematik bir hata söz konusu olabilir ve gerçekte regresyon modeline anlamlı katkısı olmayan değişkenlerin anlamlı katkı yapıyor gibi 
görünmelerine sebep olabilir (Başokçu ve Doğan, 2005). Bu varsayımın kontrol edilmesi için Durbin Watson d istatistiği kullanılmıştır. Durbin Watson d değeri .05 anlamlılık düzeyinde 1.753 eşit olup, 1.5 ve 2.5 aralığında yer alma koşulunu sağlamaktadır. Bu sonuçtan, hatalar arasında ilişki olmadığı söylenebilir.

Yukarıda ele alınan sonuçlardan çoklu regresyon analizi yapabilmek için tüm varsayımların sağlandığı sonucu çıkarılmıştır.

\section{Bulgular}

Araştırmanın birinci problemine yanıt bulabilmek için Tablo 6'da 6, 7 ve 8. sınıf öğrencilerinin Örüntü Testinden aldıkları puanların betimsel istatistik bilgilerine yer verilmiştir:

Tablo 6. Örüntü testine ilişkin betimsel istatistikler

\begin{tabular}{lccccc}
\hline & N & Ort. & SS & Min. & Max. \\
\hline ÖBT Puanı & 399 & 26.72 & 9,16 & 0 & 45 \\
\hline
\end{tabular}

Tablo 6'da göre tüm öğrencilerin örüntü testinden aldıkları en düşük puan 0 , en yüksek puan ise $45^{\prime}$ 'dir. Teste ait aritmetik ortalama 26.72 'dir.

Sınıf düzeylerine göre betimsel istatistik bilgileri Tablo 7'de verilmiştir.

Tablo 7. Sınıf düzeyine göre örüntü testi ortalamaları

\begin{tabular}{lccc}
\hline Sinıf Düzeyi & $\mathrm{N}$ & Ortalama & Standart Sapma \\
\hline 6. Sinıf & 141 & 25.72 & 0.7 \\
7. Sinıf & 119 & 22.60 & 0.7 \\
8.Sınıf & 139 & 31.27 & 0.8 \\
\hline
\end{tabular}

Tablo 7'ye göre 7. sınıfın ortalama puanının en düşük, 8. sınıfın ortalama puanının ise en yüksek olduğu görülmektedir. Ortalamaların sınıf düzeyine göre anlamlı bir farklılık gösterip göstermediğine bakmak için tek yönlü ANOVA testi kullanılmıştır. ANOVA testinin sonuçları (Tablo 8) öğrencilerin ÖBT puanlarında sınıf düzeyleri bakımından anlamlı bir fark olduğunu göstermektedir $(F=35.03, p<0.05)$. Diğer bir deyişle, öğrencilerin örüntü problemlerini çözme başarıları, öğrencilerin öğrenim gördükleri sınıf düzeyine göre anlamlı bir şekilde değişmektedir. Grup varyansları eşit olduğundan sınıf düzeylerine göre farklılıkların hangi sınıf düzeyleri arasında olduğunu bulmak amacıyla Scheffe testi kullanılmıştır. Scheffe testinin sonuçlarına göre, tüm sınıf düzeylerinde anlamlı farklılıklar elde edilmiştir. 
Tablo 8. Sınıf düzeyi değişkenine göre ANOVA sonuçları

\begin{tabular}{lccccc}
\hline $\begin{array}{l}\text { Varyansın } \\
\text { Kaynağı }\end{array}$ & $\begin{array}{l}\text { Kareler } \\
\text { toplamı }\end{array}$ & sd & $\begin{array}{c}\text { Kareler } \\
\text { ortalaması }\end{array}$ & F & p \\
\hline Gruplararası & 4888.12 & 2 & 2444.06 & 35.03 & 0.000 \\
Gruplariçi & 27896.15 & 397 & 70.267 & & \\
Toplam & 32784.27 & 398 & & & \\
\hline
\end{tabular}

Cinsiyetlerine göre öğrencilerin örüntü testi puan ortalamaları Tablo 9'da verilmiştir.

Tablo 9. Cinsiyetlerine göre öğrencilerin örüntü testi puan ortalamaları

\begin{tabular}{lccc}
\hline & $\mathrm{N}$ & Ortalama & Standart Sapma \\
\hline Erkek & 187 & 26.34 & 0.7 \\
$\mathrm{~K} 1 \mathrm{z}$ & 212 & 27.06 & 0.6 \\
\hline
\end{tabular}

Tablo 9'dan kız öğrencilerin örüntü testi puan ortalamalarının erkek öğrencilerin ortalamalarından daha yüksek olduğu görülse de bu farklılık yapılan t-testi ile istatistiksel olarak anlamlı bulunamamıştır $(t=0.79, p=0.43)$.

\section{Çoklu Regresyon Analizi}

Araştırmanın 2. problemine cevap bulmak için yapılan regresyon analizinin sonuçları Tablo 10'da verilmiştir. Yordayıcı değişkenlerle bağımlı değişken arasındaki ikili ve kısmi korelasyonlar incelendiğinde, matematik başarısının örüntü başarısını açıklamada pozitif ve zayıf düzeyde bir yordayıcı ( $r=0.26)$ olduğu; sınıf düzeyinin ise örüntü başarısını açıklamada negatif ve zayıf düzeyde bir yordayıcı $(r=-0.30)$ olduğu görülmektedir.

Tablo 10. Çoklu regresyon sonuçları

\begin{tabular}{lllllll}
\hline Değişken & $B$ & Standart Hata & $\beta$ & $t$ & $p$ & $\begin{array}{l}\text { Kısmi } \\
R\end{array}$ \\
\hline Sabit & 17.283 & 2.042 & - & 8.465 & .000 & - \\
Sinıf1 & -6.848 & .968 & -.358 & 7.077 & .000 & -.308 \\
Sinıf2 & -9.509 & 1.001 & -.476 & 9.498 & .000 & -.413 \\
Cins & -.201 & .799 & -.011 & -.252 & .801 & -.011 \\
$\begin{array}{l}\text { Matematik } \\
\text { Başarıs1 }\end{array}$ & 1.831 & .247 & .328 & 7.409 & .000 & .350 \\
\hline
\end{tabular}

$$
\begin{aligned}
& R=0.51, R^{2}=0.26 \\
& F(4,394)=33.69, p=.000
\end{aligned}
$$

Sınıf düzeyi, cinsiyet ve matematik başarısı değişkenleri birlikte, örüntü başarısı ile orta düzeyde ve anlamlı bir ilişki vermektedir $\left(R=0.51, R^{2}=0.26, p<.0000\right)$. Bu üç değişken birlikte, örüntü başarısındaki toplam varyansın yaklaşık \%26'sını açıklamaktadır. 
Standardize edilmiş regresyon katsayılarına göre, yordayıcı değişkenlerin örüntü başarısı üzerindeki göreli önem sırası sınıf düzeyi, matematik başarısı ve cinsiyet şeklindedir. Regresyon katsayılarının anlamlılığına ilişkin t-testi sonuçları incelendiğinde iki değişkenin (sınıf düzeyi ve matematik başarısı) örüntü başarısı üzerinde anlamlı bir yordayıcı olduğu görülmektedir.

\section{Tartışma ve Sonuç}

Örüntüler öğrencilerin cebirsel ve fonksiyonel düşünme becerilerinin gelişimine, problem çözme ile aritmetik becerilerine katkı sağlayan önemli bir konudur (Kılıç, 2017). Bu çalışmada sınıf düzeyi, cinsiyet ve matematik başarısının ÖBT'nden alınan puanları yordayıp yordamadığ araştırılmış ve alanyazında görülen durumlar ile karşılaştırılmıştır.

Araştırmada örüntü problemlerini çözme başarısına yönelik yapılan istatistiklerde, ortaokul öğrencilerinin iyi düzeyde örüntü başarısına sahip oldukları söylenebilir. KKTC'de uygulanan öğretim programlarında örüntü konusu okulöncesi yıllarından itibaren ele alınmaktadır. Bu durumun öğrencilerin örüntü başarılarına olumlu katkı sağladığı söylenebilir.

Öğrencilerin sınıf seviyeleri açısından örüntü problemlerini çözme başarıları incelendiğinde en düşük 7. sınıf, en yüksek 8. sınıf başarı göstermiştir. Ayrıca, birbirini takip eden sınıflar arasında anlamlı farklılıklar bulunmuştur. $\mathrm{Bu}$ durum öğrencilerin yaşı, öğretmenleri, matematiksel deneyimleri, zihinsel gelişimleri ve o sınıf seviyesindeki cebirsel düşünme ile ilgili eğitimsel materyallerin uygunluğu gibi faktörlere bağlanılabilir. Alanyazındaki birçok çalışmada (Dobrynina, 2001; Tsankova, 2003; Akkan, 2013; Yaman, 2010; Jurdak and Mouhayar, 2013; Kılıç, 2017) sınıf seviyesinin örüntü başarısını yordamada bir değişken olduğu ve sınıf seviyesi yükseldikçe öğrencilerin örüntüleri anlamada ve genellemede performanslarının arttığı belirtilmektedir. Araştırma sonuçları sınıf seviyesinin, örüntü başarısını yordamada bir değişken olduğunu ortaya koyması bakımından alanyazındaki bu çalışmalar ile benzerlik göstermektedir. Çalışmada, 7. sınıf öğrencileri ÖBT'ne en düşük performans gösteren sınıf seviyesi olması devlet koleji matematik programlarında 7. sınıf düzeyinde örüntü konusunun ele alınmaması ile açıklanabilir. Çalışmanın bulgularına göre kız ve erkek öğrencilerin ÖBT ortalamalarının farklıl1kları istatistiksel olarak anlamlı bulunamamıştır. $\mathrm{Bu}$ durum cinsiyetin örüntü başarısını yordamada anlamlı olmadığı şeklinde yorumlanabilir. Matematik başarısının öngörüldüğü üzere örüntü başarısının bir yordayıcısı olduğu çalışmanın bulguları arasındadır. Matematik konularında iyi bir performans sergileyen öğrenciler, örüntü konusunda da benzer şekilde iyi bir performans göstermişlerdir. Araştırmada, oluşturulan çoklu regresyon modeline göre, bağımlı değişken olarak kabul edilen örüntü problemlerini çözme başarısının bağımsız değişkenler olarak ele alınan sınıf düzeyi, cinsiyet ve matematik başarısından etkilendiğini görülmüştür. $\mathrm{Bu}$ üç değişken birlikte örüntü başarısını pozitif ve orta düzeyde yordamaktadır.

Yapılmış olan bu çalışmanın sonuçları göz önüne alındığında gelecekte yapılacak çalışmalar için şu öneriler verilebilir: a) Bu çalışma, bir devlet kolejinde öğrenim gören ortaokul öğrencileri ile yürütülmüştür. Benzer şekilde kurgulanacak bir araştırma daha geniş evren ve örneklemle tekrar edilebilir. b) Ortaokul öğrencilerinin örüntüleri anlama, genelleme ve düşünme süreçlerini ortaya koyacak nitel çalışmalar yapılabilir. Bu tarz çalışmalar örüntü başarısı üzerine etkili olacak başka değişkenlerin belirlenmesine yardımcı olabilir. c) Örüntü başarısı farklı değişkenler açısından incelenebilir. Öğrencilerin sosyo-ekonomik normları, 
kullanılan öğretim yöntemleri, okul türü, ders kitapları, ders çalışma alışkanlıkları gibi değişkenler örüntü başarısını şekillendirmede yordayıcı olabilir. d) Örüntü soru tiplerine ve kullanılan sunum biçimlerine göre öğrencilerin örüntü başarısının araştırılacağı çalışmalar yap1labilir.

Araştırma, 2017-2018 eğitim-öğretim y1lında, KKTC Milli Eğitim ve Kültür Bakanlığı'na bağl1, resmi bir devlet kolejinde öğrenim gören öğrenciler ve örüntü testine verdikleri cevaplar ile sinırlıdır.

Ortaokul Öğrencilerinin Örüntü Problemlerini Çözme Başarılarının Çeşitli Değişkenler Açısından Incelenmesi başlıklı çalışmanın yazım sürecinde bilimsel, etik ve alıntı kurallarına uyulmuş; toplanan veriler üzerinde herhangi bir tahrifat yapılmamış, karşıllaşılacak tüm etik ihlallerde "Pamukkale Üniversitesi Eğitim Fakültesi Dergisi Yayın Kurulunun" hiçbir sorumluluğunun olmadığı, tüm sorumluluğun Sorumlu Yazara ait olduğu ve bu çalışmanın herhangi başka bir akademik yayın ortamına değerlendirme için gönderilmemiş olduğunu taahhüt ederim. 


\section{Kaynakça}

Akkan, Y. (2013). Comparison of 6th-8th graders' efficiencies, strategies and representations regarding generalization patterns. Bolema Boletim de Educação Matemática, 27 (47), 703-732.

Becker, J. R. ve Rivera, F. (2005). Generalization strategies of beginning high school algebra students. Proceedings of the 29th Conference of the International Group for the Psychology of Mathematics Education, Melbourne.

Burns, M. (2000). About teaching mathematics. A-K 8 research (2nd ed.) Sausaluto, California. CA: Math Solutions Publication.

Dekker, T. ve Dolk, M. (2011). From arithmetic to algebra. Secondary Algebra Education, 69-87.

Dobrynina, G. (2001). Reasoning Processes of Grade 4-6 Students Solving Two- and Three-Variable Problems (Unpublished Doctoral Dissertation), Boston University, Boston.

Doğan, N. ve Başokçu, T. (2010). İstatistik Tutum Ölçeği İçin Uygulanan Faktör Analizi ve Aşamalı Kümeleme Analizi Sonuçlarının Karşılaştırılması. Journal of Measurement and Evaluation in Education and Psychology, 1 (2), 65-71.

Dyndial, J. (2007). High school students' use of patterns and generalizations. Proceedings of the 30th annual conference of the Mathematics Education Research Group of Australasia, Melbourene.

Edwards, T. (2000). Some "Big Ideas" of algebra in the middle grades. Mathematics Teaching in the Middle School, 26-31.

English, L. ve Warren, E. (1998). Introducing the variable through pattern exploration. Mathematics Teacher. 91 (2) 166-171.

Fouche, Katheryn K. (1997). Algebra for Everyone: Start Early. Mathematics Teaching in the Middle School. p. 226-29.

Hargreaves, M. Shorrocks-Taylor, D. ve Threlfall, J. (1998) Children's strategies with number patterns. Educational Studies. Vol. 24, 3.

Hargreaves, M., Shorrocks-Taylor, D. ve Threlfall, J. (1999). Children's strategies with number patterns. In A. Orton (Ed.), Pattern in the teaching and learning of mathematics (pp. 67-83). London and New York: Cassell.

Heddens, J. W., \& Speer, W. R. (2001). Today's mathematics concepts and classroom methods. New York:John Wiley and Sons.

Gravetter, J. F. ve Forzano, L. B. (2012). Research methods for the behavioral sciences. USA: Linda Schreiber-Ganster.

Jurdak, M. ve EL Mouhayar, R. (2013). Trends in the development of student level of reasoning in pattern generalization tasks across grade-level. Educational Studies in Mathematics, 85(1), 7592.

Karasar. N. (2015). Bilimsel Araştırma Yöntemi. 28. Basım. Ankara: Nobel Yayınevi.

Kılıç, Ç. (2017). Analyzing middle school students' figural pattern generating strategies considering a quadratic number pattern. Abant İzzet Baysal Üniversitesi Eğitim Fakültesi Dergisi, 17 (1), 250267.

Kieran, C. (1988). The early learning of algebra. In C. Kieran ve S. Wagner (Eds.), Research issues in the learning and teaching of algebra. Reston, VA: National Council of Teachers of Mathematics.

Köse, N. ve Tanışlı, D. (2011). İlköğretim Matematik Ders Kitaplarında Eşit İşareti ve İlişkisel Düşünme. Necatibey Eğitim Fakültesi Elektronik Fen ve Matematik Eğitimi Dergisi, 5 (2), 251-277.

Looney, C. L. (2004). A study of students' understanding of patterns and functions in grades 3-5. (Unpublished Doctoral Dissertation), Boston University, Boston. 
MacGregor, M. ve Stacey, K. (1993). Seeing a pattern and writing a rule. In I. Hirabayashi, N. Nohda, K. Shigematsu and F. Lin (Ed.), Proceeding of The 17th Conference for Psychology of Mathematics Education, 1, 181-188.

McMillan, J. H. (2004). Educational research. Boston: Pearson Education.

MacGregor, M. ve Stacey, K. (1995). The effect of different approaches to algebra on students' perceptions of functional relationships. Mathematics Education Research Journal. Vol. 7, No. 1, $69-85$

Martinez, M. ve Brizuela, B. M. (2006). A third grader's way of thinking about linear function tables. Journal of Mathematical Behavior. 25, 285-298.

Mor, Y., Noss, R., Hoyles, C., Kahn K. \& Simpson G. (2006). Designing to see and share structure in number sequences. The International Journal for Technology in Mathematics Education, 13 (2), 65.

Moss, J. ve R. Beaty. (2006). Knowledge Building in Mathematics: Supporting collaborative learning in pattern problems. Computer-Supported Collaborative Learning, 1: 441- 465.

Mulligan, J. and Mitchelmore, M. (2009). Awareness of pattern and structure in early mathematical development. Mathematics Education Research Journal, 21 (2), 33-49

National Council of Teachers of Mathematics. (1989). Curriculum and Evaluation Standards for School Mathematics. Reston, VA: NCTM

National Council of Teachers of Mathematics. (NCTM) (2000). Principles and standards for school mathematics. Reston, VA: Author.

Olkun, S. ve Toluk-Uçar, Z. (2007). İlköğretimde Etkinlik Temelli Matematik Öğretimi. Ankara: Maya Akademi.

Olkun, S. ve Yeşildere, S. (2007). Sınıf Öğretmeni Adayları İçin Temel Matematik 1. Ankara: Maya Akademi.

Orton, A. (1999). Preface. In A. Orton (Ed.), Pattern in the Teaching and Learning of Mathematics. London and New York: Cassell.

Orton, A. ve Orton, J. (1994). Student's perception and use of pattern and generalization, Proceedings of the Eighteenth. Conference for Psychology of Mathematics Education, s. 407-414.

Orton, A. and Orton, J. (1999). Pattern and the approach to algebra. In A. Orton (Ed.), Pattern in the Teaching and Learning of Mathematics. s. 104-120. London: Cassel.

Orton, J., Orton, A. ve Roper, T. (1999). Pictorial and Practical Context and the Presentation of Pattern. In A. Orton (Ed.), Pattern in the Teaching and Learning of Mathematics. s. 121-136. London: Cassel.

Özdemir, E., Dikici, R. ve Kültür, N. (2014). Öğrencilerin Örüntüleri Genelleme Süreçleri: 7. Sınıf Örneği. K. Ü. Kastamonu Eğitim Dergisi, 23(2), 523-548.

Papic, M. (2007). Promoting repeating patterns with young children. Australian Primary Mathematics Classroom, 12(3), 8-13.

Palabıyık, U., Akkuş İspir, O. (2011). Örüntü temelli cebir öğretiminin öğrencilerin cebirsel düşünme becerileri ve matematiğe karşı tutumlarına etkisi. Pamukkale Üniversitesi Ĕ̆itim Fakültesi Dergisi, 30, 111-123.

Pilten, P ve Yener, D. (2013). İlköğretim 1. Kademe Öğrencilerinin Matematiksel Örüntüleri Analiz Etme ve Tahminde Bulunma Becerilerinin Değerlendirilmesi. Sakarya Üniversitesi Eğitim Fakültesi Dergisi, 18, 62-78.

Schliemann, A.D., Carraher, D. W. ve Brizuella, B. (2001). When tables become function tables. Proceedings of the 25th Conference of the International Group for the Psychology of Mathematics Education. Utrecht, The Netherlands 
Schliemann, A.D., Goodrow, A. ve Lara-Roth, S. (2001). Functions and graphs in third grade. NCTM 2001 Research Precession. Orlande. FL.

Schliemann, A.D., Carraher, D. W., Brizuella, B., Earnest, D. Goodrow, A., Lara-Roth, S. ve Peled, I. (2003). Algebra in elementary school. Proceedings of the 27th International Conference for the Psychology of Mathematics Education. Honolulu, HI

Steen, L. A. (Ed.) (1990). On the shoulders of giants: New approaches to numeracy. Washington DC: National Academy Press.

Tall, D. (1992). The transition from arithmetic to algebra: Number patterns or proceptual programming? New Directions in Algebra Education. Brisbane: Queensland.

Tanışl1, D. (2008). Illköğretim beşinci sinıf öğrencilerinin örüntülere ilişskin anlama ve kavrama biçimlerinin belirlenmesi. (Yayınlanmamış Doktora Tezi), Eskişehir, Türkiye

Tanışlı, D., Yavuzsoy, N., \& Camcı, F. (2017). Matematik öğretmen adaylarının örüntüler bağlamında genelleme ve doğrulama bilgileri. Eğitimde Nitel Araștırmalar Dergisi, 5(3), 195-222.

Tanışl, D. ve Olkun, S. (2009). Basitten Karmaşığa Örüntüler. Ankara: Maya Akademi.

Tsankova, I. (2003). Algebraic reasoning of first through third grade students solving systems of two linear equations with two variables. (Unpublished Doctoral Dissertation), Boston University, Boston.

Threlfall, J. (1999). Repeating patterns in the early primary years. In A. Orton (Ed.), Patterns in the teaching and learning of mathematics. London: Cassell.

Uygur-Kabael, T., ve Tanışlı, D. (2010). Cebirsel düşünme sürecinde örüntüden fonksiyona öğretim. Ilköğretim Online, 9(1), 213-228.

Warren, E. (2004). Generalizing arithmetic: supporting the process in the early years. Proceedings of the 28th Conference of the International Group for the Psychology of Mathematics Education, Vol 4., s.417-424

Warren, E. (2005). Patterns supporting the development of early algebraic thinking. In P. Clarkson, A. Downton, D. Gronn, M. Horne, A. McDonough, R. Pierce, \& A. Roche (Eds.), Building connections: Research, theory and practice. Proceedings of the 28th annual conference of the Mathematics Education Research Group of Australasia, Melbourne, s. 759-766). Sydney: MERGA.

Warren, E. ve Cooper, T. (2006). Using repeating patterns to explore functional thinking. Australian Primary Mathematics Classroom, 11(1), 9-14.

Warren, E. (2009). Early childhood teachers' professional learning in early algebraic thinking: a model that supports new knowledge and pedagogy. Mathematics Education Research Journal, Vol. 9, $30-45$.

Willoughby, S.S. (1997). Functions from kindergarten through sixth grade. Teaching Children Mathematics, 3, 314-318.

Yackel, E. (1997). Explanation as an interactive accomplishment: A case study of one second-grade mathematics classroom. Paper presented at the annual meeting of the American Educational Research Association, Chicago.

Yaman, H. (2010). İlköğretim öğrencilerinin matematiksel örüntülerdeki ilişsileri algılayışları üzerine bir inceleme (Yayınlanmamış Doktora Tezi), Ankara, Türkiye.

Yeşildere, S. ve Akkoç, H. (2010). Matematik öğretmen adaylarının sayı örüntülerine ilişkin pedagojik alan bilgilerinin konuya özel stratejiler bağlamında incelenmesi. On Dokuz Mayls Üniversitesi Eğitim Fakültesi Dergisi, 29(1), 125-149. 


\section{Extended Abstract}

\section{Introduction}

Pattern is one of the important mathematical concepts involved in mathematics education. There are many definitions of pattern in the literature. A pattern can be defined as a systematic configuration of geometric figures, sounds, symbols, and actions. Papic and Mitchelmore (2005) asserted that a mathematical pattern may be described as any predictable regularity, usually involving numerical, spatial or logical relationships.

The purpose of this study was to determine whether there is a significant relationship between the grade level, gender and mathematics achievement of secondary school students and their success in solving pattern problems. In this context, it is aimed to determine the success of students about the patterns and to provide data to see the development algebraic and functional thinking of students. It is thought that the results of the study will contribute to the studies conducted in the field of mathematics education in TRNC.

By sticking to the literature it was observed that gender, grade level, and mathematics variables discussed in this study were differentiating variables in some studies and they were selected for evaluation in this study. For the main purpose of the research, the following questions were sought: a) What is the level of secondary school students' pattern achievement? b) Does the grade level, gender, and mathematics achievement predict the pattern achievement significantly?

\section{Method}

The research aims to determine the existing conditions of the patterns' success of students, therefore it is a survey model. Surveying models are the research approaches which aim to describe a past or existing situation as it is. The samples of the research are 399 middle school students at a government college in Nicosia district in TRNC, and they were determined through convenience sampling method. This school was picked and the students in these schools were sampled for the reason that the schools are close to where the researchers reside and that it would be an easy and low cost application.

In the research, 'Pattern Achievement Test' was used, which was developed by the researchers based on the relevant literature in order to collect data. The students who scored high on the test are considered to have high pattern achievement. Pattern Achievement Test was distributed to the students and they were given 40 minutes to answer to questions. Before the application the students were informed about the subject and the duration of the test. Further, a Consent Form was read and signed before students before starting test. Since the students were under the age of 18 , their parents were also allowed to their students participate the research. Before the application, the students were informed about the subject of the scale and the response time.

The scoring of the test was based on the sub-questions contained in each question. The total score of each student was calculated using this scoring system. Two mathematics teachers were consulted for scoring. A statistical package program was used for data analysis. To determine the effects of independent variables on the pattern's achievement of students, t-test, ANOVA and multiple regression analysis was used. 


\section{Results}

The lowest score of students from the test was 0 and the highest score was 45 . The mean of the test was equal to 26.72 . The results show that the 8 th grade class had the highest average on test. The lowest average level was gained by the 7 th grade students.

The mean score of the girls was higher than the average of boys but the mean difference was not statistically meaningful. When the correlations between the predictive variables and the dependent variable were examined, it was found that mathematics achievement was a positive and weak predictor $(\mathrm{r}=0.26)$ in explaining the pattern achievement.

Class level, gender and mathematics achievement variables together predicted moderate and significant relationship with pattern success $(\mathrm{R}=0.50, \mathrm{R} 2=0.26, \mathrm{p}<.0000)$. Together, these three variables explain approximately $26 \%$ of the total variance of pattern achievement.

\section{Discussions}

In this study, it was investigated how the performance of middle school students' patterns about some variables (grade level, gender and mathematics achievement) used as predictor. Findings of the study were shown that middle school students had a good level of success about patterns.

In the curriculum of TRNC, the subject of pattern is started from the elementary school years. It can be said that this situation positively contributes to the students' pattern achievements.

In the study, it was observed that the grade level, gender and mathematics achievement which were considered as independent variables predicted the pattern achievement of the students. These three variables predicted the pattern achievement at a positive and moderate level. In particular, when a number of research results for the class level variable were reached in the literature, it reveals that the grade level was a variable in predicting the pattern achievement. This situation coincides with some studies in the literature. In this way, significant differences between students' mathematical pattern performances in terms of class levels can be attributed to factors such as age, mathematical experiences, mental and physical development of students, and the suitability of educational materials related to algebraic thinking at specific grade level. The results of the research make known that mathematics achievement was a predictor of the pattern achievement. The students who performed well in mathematics subject showed a similar high performance in patterns.

According to the results of the study, the mean of pattern achievement test of girls and boys was found very close to each other. This may be interpreted as there was no significant difference between their pattern achievements.

Considering the results of this study, the following suggestions may be given regarding future studies: a) further studies in this field may be conducted on different sampling groups and the results may be compared. b) Qualitative studies may be carried out to understand students' generalization and thinking process. c) Pattern achievement can be examined in terms of different variables. d) Studies can be conducted to investigate the pattern achievement of students in terms of pattern types and their presentation styles. 